\section{Automatic Electrical Farm Boiler}

IN the Electrical Review of June 6, Mr. Theodore Rich gives a complete description of an apparatus developed particularly in the province of Brandenburg in Germany whereby steamed potatoes are prepared for pig food. The steamer consists of a galvanized cylindrical vessel, with an insulating jacket and lid. It is mounted on bearings like a churn, and is fitted with a tipping-locking lever. Three sizes are made for about 80, 155 and $308 \mathrm{lb}$. of potatoes respectively. The potatoes and necessary water are put in at night, and thanks to automatic control, the potatoes are correctly cooked by the early morning. The food keeps warm throughout the day without the apparatus being switched on and the operational cost is low owing to the special low night rates. The apparatus is protected against running dry. It is claimed that the floury product is much liked by stock.

\section{Basic Costs in Electricity Supply}

ONE of the principal problems in the management of public electricity supply companies is how to reconcile the costs with the charges not only from year to year but also in their irregular secular changes. Cost data are a matter of fact, but the application of such facts to the special circumstances of individual cases is often a question of policy. There are many ways of segregating and arranging cost data, although any process of segregation so far as electricity is concerned is entirely empirical. Some method of averaging has necessarily to be adopted, and probably the greatest difficulty lies in the determination of the proper allowances to be made for load diversity. As Mr. G. D. Bond points out in the Electrician of May 2, each extension of the field of development makes the problem harder, and it is hardest when the variety of the load on the public network is the greatest. A modern factor which increases the difficulty of diversity-measurement is arising in those undertakings, where, owing to the development of new loads, there is a consequent shift in the time of incidence of the peak-load.

In addition to the short-term division of costs as 'fixed' and 'running', there is a long-term division of costs into 'differential' and 'residual' costs. This latter division of costs may be explained by considering the domestic and commercial development of load, which is necessarily a long-term process. Up to a point, extra supplies can be given without recourse to additional capital expenditure (particularly when the demands are extensive and not intensive) ; later on, as local network difficulties arise, some fortification of mains is required, until at a later stage heavy capital expenditure is needed to cope possibly with peak loads of relatively short duration. At this point, the short-term supposition of cost incidence becomes invalid because the differential cost of giving the extra supplies is higher than the residual cost. With intensive development the differential cost decreases provided selective loads are taken to improve consumers' loads and diversity factors.

\section{Franklin Institute Medallists}

THe complete list of medal awards by the Franklin Institute (see NATuRE, July 5, p. 19) is now available: Franklin Medals : Sir C. V. Raman; Prof. E. H. Armstrong, professor of electrical engineering, Columbia University; Cresson Medal: The United States Navy, received by the Hon. Ralph A. Bard, assistant secretary of the Navy, Washington, D.C. ; Potts Medal: Prof. H. E. Edgerton, associate professor of electrical engineering, Massachusetts Institute of Technology; Levy Medal: Profs. J. M. Lessells and C. W. MacGregor, of the Massachusetts Institute of Technology ; Clark Medal : Raymond Mower Conner, director of the Testing Laboratories, American Gas Association, Cleveland ; Brown Medal : W. H. Carrier, chairman of the board, Carrier Corporation, Syracuse; Wetherill Medal : H. S. Black, Bell Telephone Laboratories, New York City ; Longstreth Medal : B. J. Wilson, chief of the mechanical division, Research Department, Leeds and Northrup Company, Philadelphia.

\section{Magnetic Storm}

A MAGNETIC storm was registered at Abinger on July 5. The storm began at $6 \mathrm{hr}$. and remained intense until $16 \mathrm{hr}$. G.M.T. The range in declination was $1^{\circ} 17^{\prime}$; in horizontal intensity, $950 \gamma$; in vertical intensity, $745 \gamma$.

\section{Announcements}

Prof. Emil Abderhalden, professor of physiology in the University of Halle, has been made an honorary member of the Société de Physique et d'Histoire naturelle of Geneva.

Prof. Prccinini has founded an Institute for the History of Medicine at the University of Milan. where he occupies the chair in that subject.

The University of Oxford is making a grant to the Department of Chemistry to carry out a nutritional survey and a study of antiseptics in relation to burns.

THE Ministry of Health is arranging for children attending clinics to have black currant syrup made from a formula drawn up by the Long Ashton Research Station (University of Bristol). Black currants are well known to be very rich in ascorbic acid, and the syrup is stated to contain five times the vitamin $\mathrm{C}$ content of orange juice.

The British Psychological Society is arranging a whole-day meeting to be held in London on July 26 to discuss psychological problems of air-raid shelters and evacuation. Those interested should communicate with the honorary general secretary, Mr. R. J. Bartlett, 14 Barchester Road, Harrow Weald, Middlesex.

According to the latest report of the RegistrarGeneral the highest marriage-rate ever known in Great Britain occurred in 1940. Marriages in England and Wales totalled 468,267 and exceeded the record figure in 1939 by 28,573 ; the marriage-rate per 1,000 of the population was $22 \cdot 6$, and the previous highest rate except for 1939 was 20.2 in 1920. During the War of 1914-18 the highest marriage-rate was in 1915 . 